\title{
How Do Parents See? The Relationship between Sport Participation and Quality of Life among Boys with ADHD: A Cross-Sectional Study
}

\author{
Martina Miklós ${ }^{1,2 *}$, Judit Futó ${ }^{2}$ and Judit Balázs ${ }^{2,3}$ \\ ${ }^{1}$ Doctoral School of Psychology, Eötvös Loránd University, Budapest, Hungary \\ ${ }^{2}$ Eötvös Loránd University, Institute of Psychology, Budapest, Hungary \\ ${ }^{3}$ Bjørknes University College, Oslo, Norway
}

Submission: February 7, 2019; Published: February 25, 2019

*Corresponding author: Martina Miklós, Doctoral School of Psychology, Eötvös Loránd University, 1064 Izabella st. 46. Budapest, Hungary

\begin{abstract}
Background: Attention deficit/hyperactivity disorder (ADHD) is a common neurodevelopmental disorder in childhood that occurs in approximately 4-6\% of children between the age 6 and 12 and is associated with several negative consequences that affect the children's functioning across different life settings. Recently, physical activity has become the focus of various studies investigating its role as a potential intervention for managing cognitive and affective consequences and symptoms of ADHD. To our knowledge, there is a gap in the literature about the relationship between sport participation and quality of life (QoL) of children with ADHD.

Methods: Parents of boys diagnosed with ADHD ( $N=45)$ completed the Inventar Lebensqualität Kindern und Jugendlichen (ILK) to measure the QoL of children (QoLp); the Strength and Difficulty Questionnaire (SDQ), which measures the behavioral and emotional characteristics of children the ADHD Rating Scale, which estimates the symptoms of ADHD; and the Rosenberg Self-esteem Scale (RSES) to assess parents' global self-esteem. A demographic data sheet was used to get information about sport activity.

Results: The QoLp score was significantly lower (meaning significantly better QoL) among ADHD boys who engaged in regular sport activity than ADHD boys who did not ( $\mathrm{t}(43)=-3.87, \mathrm{p}<.001$ ). Additionally, the Global Problem scores (as rated by the parents) of the group of boys with ADHD who engaged in regular sport activity were significantly lower $(t(43)=-3.27, p=.002)$ than that of ADHD boys who did not. Parents' Global Self-Esteem scores were significantly higher $(\mathrm{t}(43)=-2.05, \mathrm{p}=.047)$ among parents of boys with ADHD who engaged in regular sport activity than among parents of boys with ADHD who did not. Both the Global Problem score $(\mathrm{F}(1,42)=22.754, \mathrm{p}<.001)$ and participating or not in regular sport activities $(F(1,42)=4.498, p<.040)$ were found to have significant main effects on QoLp, however only the current frequency of sport activity was a significant predictor of children's QoLp.
\end{abstract}

Conclusion: During the treatment of children living with ADHD it is essential to pay attention to the children's QoL. Regular sport activity can be related to better QoL and reduced problematic behaviour.

Keywords: Attention deficit/hyperactivity disorder; ADHD; Children; Boys; Sport Participation; Quality of Life; QoL, Problematic Behaviour.

\section{Background}

Attention deficit/hyperactivity disorder (ADHD) is a common neurodevelopmental disorder in childhood that occurs in approximately $4-6 \%$ of children between the age of 6 and 12 [1,2]. It is estimated that boys are three times more likely to have ADHD than girls $[3,4]$. The symptoms, which consist of inattention, hyperactivity, and impulsivity, interfere with functioning across different life settings [5]. ADHD is associated with several negative consequences, such as reduced academic performance, low self-esteem, deficits in social skills, peer rejection and comorbid mental health problems including anxiety and depression $[6,7]$.
The most effective treatments for reducing ADHD symptoms are medications (i.e. stimulants and atomoxetine) and behavioral interventions $[2,8,9]$.

ADHD not only affects the quality of life (QoL) of the child but also that of their parents and siblings [10]. A very early study discovered that parents of children with severe ADHD demonstrated greater impairment in social and psychological functioning [11]. In another study, researchers examined the relationship between parental self-confidence, warmth and involvement in families of children with ADHD in Iranian population [12]. They reported 


\section{Psychology and Behavioral Science International Journal}

that parents of children with ADHD had lower self-confidence and less warmth and involvement with their children than the parents of healthy control children [12].

Over the past half-century, scientific data have continued to gather evidence that being physically unfit and/or having an inactive lifestyle has major negative health consequences throughout the lifespan [13]. Physical activity, in general has been shown to have a wide range of beneficial effects on health and well-being. Furthermore, a growing number of studies showed that engagement in various forms and levels of intensity of physical activity have been associated with improved executive functions, social skills and affect together with lower levels of impulsivity, hyperactivity, inattention, anxiety and depression among individuals with ADHD [14-18].

The possible association between sport participation and the management of ADHD symptoms has also been investigated [19]. In one study, parents reported that 6-14 year-old children with ADHD who played three or more sports showed fewer symptoms of anxiety and depression than those who played two or fewer sports [20]. Based on parental reports as well, Johnson's and Rosén's [21] study found that boys with ADHD, age 6-17 years old, participated in team sport for a significantly shorter period of time, demonstrated aggression and emotional reactivity and were disqualified more frequently than boys who did not have ADHD. Similarly, Harvey et al. [22] reported that 9-12 year-old boys with ADHD spend less time doing daily physical activity and organized sport than boys without ADHD.

Quality of Life (QoL) is defined by the World Health Organization as ,an individual's perception of their position in life in the context of the culture and value systems in which they live and in relation to their goals, expectations, standards and concerns [23]. Comprehending the impact of mental disorders-specifically ADHD on QoL allows observation of different levels of impairment. Marques et al. [24] found that 8-12-year-old children living with ADHD (without any comorbidities) had signficantly lower QoL in all dimensions when compared to typically developing children (based on both self- and parents' reports). Moreover, their results showed that the physical functioning and emotional functioning dimensions did not diverge significantly between the groups.

Gapin and Etnier [25] were the first to gather empirical evidence about parents' thoughts on how physical activity affects ADHD symptoms in their children. They found that physical activity was perceived to be an important moderator of the behavioral symptoms of 5-17-year-old children with ADHD and its effectiveness was evident even beyond the effects of the pharmacological treatment. There is little research, however, about the possible connection between sport participation and QoL of children with ADHD. The aim of the current study was to examine whether parents of boys with ADHD who were involved in regular sport activity reported better QoL for their children and less problematic behaviour than parents of boys with ADHD who were not involved in regular sport activity. We also explored potential predictors of children's QoL. Furthermore we examined the relationship betwe- en the frequency (hours per week) of current sport activity and the children's QoL as rated by the parents $\left(\mathrm{QoL}_{\mathrm{p}}\right)$.

\section{Materials and Methods}

\section{Subjects}

The sample was recruited from the Vadaskert Child Psychiatric Hospital and Outpatient Clinic, Budapest, Hungary between February and November 2016. The cachment area of the hospital is from all parts of Hungary. This paper presents data for 45 treatment naive boys with ADHD (age: $\mathrm{M}=8.24$ years, $\mathrm{SD}=1.48$, aged 6-11 years). Of this sample, twenty-four boys with ADHD were involved in regular sport activity, while twenty-one were not participating in sport on a regular basis. Sport activity was defined to be regular if the child had been participating in sport for at least a month before her/his participation in the study. Inclusion criterion were that the children had to be over 6 and under 12 years old with a diagnosis of ADHD. ADHD diagnosis was based on a structured diagnostic interview.

Exclusion criteria were intellectual disability and autism in the medical history. The study was approved by the Ethical Committee of the Medical Research Council, Hungary (ETT-TUKEB). The parents of each child included in this study provided written informed consent after having been informed of the nature of the study.

\section{Measures}

\section{Mini International Neuropsychiatric Interview Kid}

We determined psychiatric pathology with the modified version of the Hungarian Mini International Neuropsychiatric Interview for Children and Adolescents (MINI Kid) [26-30]. The MINI Kid is a short, structured diagnostic interview, assessesing 25 child psychiatric disorders, including ADHD, according to the Diagnostic and Statistical Manual of Mental Disorders-Fourth Edition (DSM-IV) [31].

Sheehan et al. [30] investigated the concurrent validity and reliability of the MINI Kid in a sample of 226 children and adolescents (190 outpatients and 36 controls) aged 6 to 17 years. For purposes of evaluating concurrent validity, the Schedule for Affective Disorders and Schizophrenia for School Aged ChildrenPresent and Lifetime Version was administered as well. Interrater reliability data were collected for 57 children and in the case of 83 children, test-retest reliability data. Sheehan et al. [30] found good to excellent concordance for the diagnoses of mood disorders, anxiety disorders, substance use disorders, ADHD, behavioral disorders, and eating disorders (area under the curve $=.81-.96, \kappa=$ .56-.87) and medium concordance for psychotic disorders (area under curve $=.94, \kappa=.41)$. Sensitivity was reported as very good to excellent (.61-1.00) for 15 of 20 disorders and acceptable (> $.40)$ in the case of 5 disorders. Specificity was excellent (.81-1.00) for 18 out of 20 disorders and very good $(>.73)$ for the remaining 2 disorders (hypo/manic episode, ADHD). Interrater and test-retest were very good to excellent $(\kappa=.64-1.00)$ for all disorders except dysthymia $(\kappa=.41)$. 
Balázs et al. [26] developed the Hungarian version of the MINI Kid. The high quality of the Hungarian translation of the MINI Kid was guaranteed by a multistep translation procedure, containing initial translation, back translation, harmonization, and pilot study [26]. The MINI Kid was administered to 112 children aged $<18$ years old during the validation. Two interviewers interviewed 51 children, and in the case of 31 children, the interview was repeated a second time within 48 hours. The reliability of the MINI Kid was found to be good to excellent, except in the case of testretest reliability for generalized anxiety disorder $(\kappa=.36)$. In our study, children were interviewed with their parents according to the instruction of the MINI KID administration procedure [26,30]. Interviewers underwent a standardized training procedure before going live, and their work was overseen.

\section{Rosenberg Self-Esteem Scale}

The Rosenberg Self-esteem Scale (RSES) has been relevant worldwide for the measurement of general self-esteem (RSES) $[32,33]$. The RSES was translated into 28 languages, including Hungarian, and administered to 16,998 participants across 53 nations [33]. The internal reliabilities (Cronbach alphas) of the RSES scale within 53 nations showed that the mean reliability across all nations was substantial $(\alpha=.81)$. Sallay et al. [34] tested an alternative Hungarian translation for factorial structure, structural invariance, and other psychometric properties. They analyzed data from four cross-sectional questionnaire studies (N $=1702, \mathrm{n}_{\text {male }}=674, \mathrm{n}_{\text {female }}=1025$ ). The factorial structure of the RSES-H corresponded to the previously published bifactorial model (one general latent self-esteem factor and two ,methodological' latent factors for the negatively and positively worded items). This was found to be invariant across the subsamples. Measures of internal consistency were adequate (Cronbach's alphas $\geq .857$ ). Level of self-esteem was mostly independent of sociodemographic characteristics (gender, age, and education), as well as of social desirability. Sallay et al.'s [34] work recommends this alternative Hungarian translated version as a valid and reliable questionnaire for measuring the level of global self-esteem.

\section{Inventar Lebensqualität Kindern und Jugendlichen}

The self and the parent rated versions of the Inventar Lebensqualität Kindern und Jugendlichen (ILK) were used to measure the QoL of children [35,36]. This questionnaire can measure the QoL of healthy as well as clinical samples [36]. During the Hungarian validity study of ILK, data were analyzed from 2620 children and their parents (mean age: 10.45 years, sd: 2.2 years) [36]. The internal reliability was adequate (Cronbach's alphas $>.6$ ) in all three versions (children, adolescent, parent). The range for test-retest reliability was between .67 and .75. The ILK is well suited for both global and detailed examinations of QoL in Hungarian child populations.

The children's variant of the ILK contains 7 questions and can be used for children from ages 6 to 12 . In the parents' version the parents have to assess their children's QoL. In addition to general QoL the ILK evaluates 6 specific areas: school, family, peer relationships, time spent independently, physical health and mood. There are two additional areas when using the ILK on a clinical sample: how the problem/disorder affects the children's QoL and what effects (positive or negative) do the treatments and examinations have on the children. In the version for clinical populations, the parents also have to assess their feelings about their children's disorder. In the parental version, parents have to calculate the time their children spend in school, doing homework, with family, with friends, alone, and sleeping.

\section{Strength and Difficulty Questionnaire}

The Strength and Difficulty Questionnaire (SDQ) was developed by Robert Goodman [37]. It measures the behavioral and emotional characteristics of children from ages 4 to 16 and can be completed by the adolescents, their parents, or their teachers. The questionnaire assessess not only the problematic areas, but also the children's abilities (prosocial behaviour). Goodman [37] found that the scale demonstrated sufficient reliability (alpha = .073).

The SDQ has 25 items, which can be classified into 5 scales (Hyperactivity, Emotional symptoms, Behavioral problems, Peer-relationship difficulties, Prosocial behaviour). The Global Problem score can be calculated by summing the scores on each scale (except the scores on the Prosocial scale). The Hungarian applicability of the SDQ data was assessed based on 156 children's parents' ratings (age between 62-87 months, mean age: $75 \pm 4$ months) [38]. The internal consistency ranges from moderate to acceptable (Cronbach's alphas between .43-.70). However, the mean global problem scores (11.0) were much higher among the group of children age 6 than the same age groups measured in West-European and North-American samples. However, the authors suggest that the Hungarian version of the SDQ can be used for measuring and following Hungarian children's and adolescents' mental health [38]. The validation of the Hungarian version of the SDQ was carried out with both the adolescents from the general population and clinical populations [38,39]. The selfrating and parental versions of the SDQ were completed by 716 adolescents, recruited from the Vadaskert Child and Adolescent Psychiatric Hospital, Budapest, Hungary, and their parents. Internal consistency extended from moderate to adequate (.55.79). The version parents completed about their kids seemed to be more reliable than the adolescent self-rating version. The questionnaire distinguished exceedingly well between the control and clinical groups using the global problem scores and the scales. Parents in the clinical group rated their child's mental and behavioral problems as more severe than parents from the control group. These results suggest that the Hungarian version of the SDQ can be used in a clinical sample as well [39].

\section{ADHD Rating Scale}

The ADHD Rating Scale [40] is a checklist that evaluates the presence of symptoms of ADHD, according to the diagnostic criteria of the Diagnostic and Statistical Manual of Mental Disorders (DSM-IV), in a dimensional way [31]. The ADHD Rating Scale has 
18 items, which can be devided into two subscales: Inattention and Hyperactivity-Impulsivity. Each item is rated on a 4-point Likert scale, using responses such as ,never or rarely', ,sometimes', ,often', or ,very often'. It has two versions: the school version (rated by teachers) and the home version (rated by parents). The test-retest reliability, internal consistency, and criterion-related validity of the instrument were examined using a portion of the same sample of 71 students (ages 5-17 years old). Alpha coefficients for the school version were .94 for total score, .96 for inattention and .88 for hyperactivity-impulsivity. Alpha coefficients for the home version were .92 for the total score, .86 for inattention and .88 for hyperactivity-impulsivity.

\section{Demographic Questionnaire}

A structured questionnaire was specifically developed for this study to explore the demographic characteristics of the participants, such as parents' education and economic activity, family structure, children's motor development and their involvement with sport activity.

\section{Procedures}

\section{Diagnostical and Additional Questionnaires Phase}

Children were recruited from the Vadaskert Child Psychiatric Hospital and Outpatient Clinic, while staying on a ward in the hospital. Children with ADHD were identified via an initial screening process in which the child-parent diads were interviewed with the MINI Kid on the first day in the hospital. If the diagnosis was stated by the MINI Kid and the children's own childpsychiatrist has varifid the diagnosis, additional qestionnaires were given to the parents (demographic questionnaire, SDQ, ILK, RSES, ADHD Rating Scale, as listed above).

\section{Statistical Analysis}

All statistical analyses were performed using SPSS (Version 22.0) for Windows. Initially, the Kolmogorov-Smirnov test was used to examine the distribution of the numerical variables. Then we examined whether boys who play sport on a regular basis have better QoL (as rated by their parents, see further as $\mathrm{QoL}_{\mathrm{p}}$ ) and fewer behaviour problems (as indicated by the Global Problem scores of SDQ) than do boys who do not participate in regular sport activities. Further we examined whether higher global parental self-esteem is seen if the son participates in regular sport activities. A global QoL $\mathrm{p}_{\mathrm{p}}$ index score was calculated from the average of items $1,2,3,4,6$ and 7 of the QoL scale, as these are the items of the questionnaire that are directly related to the children's QoL. The fifth item (physical health) was excluded because it is concerned with the physical health rather than the psychological well-being of the child. The fifth item being different from the rest of the questionnaire is further supported by its low item-total correlation $(r=.16)$. We used independent sample t-test to examine these hypotheses.

Next, we tested whether Global Problem scores, Global Hyperactivity scores and Parents' Global Self-Esteem scores (Rosen) were potential predictors of children's QoL $_{\mathrm{p}}$, using Multiple regression analysis (stepwise model). The terms for the regression analysis were acceptable.

We continued with Univariate Analysis of Variance to examine the effects of Global Problem scores and regular sport activity on $\mathrm{QoL}_{\mathrm{p}}$. Levene's test check for homogeneity of variances were non significant $(p=.646)$. Finally, we analyzed the relation among the frequency (hours per week) of current sport activity and the quality of life of the child ( $\mathrm{QoL}_{\mathrm{p}}$ ) by Linar regression analysis (enter model). The terms for the regression analysis here were also acceptable.

\section{Results}

\section{Participants}

Altogether 45 boys with ADHD (mean age in years: 8.24 $(\mathrm{SD}=1.48)$ ) were enrolled in the study. The mean age of ADHD boys who engaged in regular sport activity was 8.29 ( $\mathrm{SD}=1.49$ ), while the mean age of ADHD boys who did not regularly participate in sport activity was 8.19 (SD =1.50). The two groups did not differ from each other significantly with respect to age (U=249.50, Z= $-.058, \mathrm{p}=.954$ ). Table 1 provides an overview of participant characteristics.

Table 1: Sample Characteristics ( $N=45$ children with ADHD).

\begin{tabular}{|c|c|c|}
\hline \multicolumn{2}{|c|}{ Sample (N=45) Characteristics } & $\begin{array}{c}\text { Frequencies (per- } \\
\text { sons) }\end{array}$ \\
\hline Gender & Boys & 45 \\
\hline \multirow{3}{*}{$\begin{array}{c}\text { Highest educational } \\
\text { level (SES) }\end{array}$} & $\begin{array}{c}\text { University degree } \\
\text { (mothers) }\end{array}$ & 25 \\
\cline { 2 - 3 } & $\begin{array}{c}\text { University degree } \\
\text { (fathers) }\end{array}$ & 15 \\
\hline \multirow{3}{*}{$\begin{array}{c}\text { Children's place of } \\
\text { residence }\end{array}$} & Capital & 24 \\
\cline { 2 - 3 } & Town & 10 \\
\hline \multirow{2}{*}{$\begin{array}{c}\text { Children's current } \\
\text { educational institute }\end{array}$} & Village & 11 \\
\cline { 2 - 3 } & Elementary school & 38 \\
\hline \multirow{2}{*}{$\begin{array}{c}\text { Children's family } \\
\text { setting }\end{array}$} & Lives in family & 7 \\
\cline { 2 - 3 } & Adopted & 42 \\
\cline { 2 - 3 } & Lives with fosterer(s) & 2 \\
\hline
\end{tabular}

Parents' rating of their son's QoL (QoL $)$, Global Problem scores and the Parents' Global Self-Esteem scores (boys who do sport regularly versus those who do not)

Parents of boys who played sport on a regular basis rated their son's QoL $(\mathrm{N}=24 ; \mathrm{M}=2.02, \mathrm{SD}=.59)$ to be significantly better $(\mathrm{t}(43)=-3.87, \mathrm{p}<.001)$ than parents of boys who did not exercise regularly $(\mathrm{N}=21 ; \mathrm{M}=2.67, \mathrm{SD}=.53)$. The Global Problem scores (as rated by the parents) of the boys who played sport regularly $(M=16.38, S D=4.84)$ was also significantly lower $(t(43)=-3.27$, $\mathrm{p}=.002)$ than that of the physically inactive group $(\mathrm{M}=21.14, \mathrm{SD}=$ 4.93). Parents' Global Self-Esteem scores were significantly higher $(t(43)=-2.05, p=.047)$ among parents of boys engaged in regular 
sport activity $(\mathrm{M}=33.33, \mathrm{SD}=4.78)$ than parents of boys who did not participate in sport acitivity regularly $(M=29.62, S D=7.28)$.

Global Problem scores, Global Hyperactivity scores and Parents' Global Self-Esteem score (Rosen) as potential predictors of children's QoL $_{p}$

Multiple regression analysis (stepwise model) was used to test if the Global Problem score and/or Global Hyperactivity score and/or Parents' Global Self-Esteem score significantly predicted children's QoL $_{\mathrm{p}}$. The results of the regression indicated that the only independent variable that proved useful for predicting QoL $\mathrm{p}_{\mathrm{p}}$ was the Global Problem score $\left(\mathrm{R}^{2}=.467\right.$, adjusted $\mathrm{R}^{2}=.455$, $F(1,43)=37.707, p<.001, \beta=.684, p<.001)$. Both the Global Hyperactivity score $(\beta=.012, p=.927)$ and the Parents' Global SelfEsteem score $(\beta=-.099, p=.394)$ were excluded from the model.

Analysing the effects of Global Problem scores and regular sport activity on QoL $\mathrm{L}_{\mathrm{p}}$ (Univariate Analysis of Variance)

Both the Global Problem score $(F(1,42)=22.754, p<.001)$ and participating or not in regular sport activities $(F(1,42)=4.498$, $\mathrm{p}<.040$ ) were found to have significant main effects on $\mathrm{QoL}_{\mathrm{p}}$ Those with lower overall Global Problem scores were reported to have better $\mathrm{QoL}_{\mathrm{p}}$ than did boys with more problem behaviours. Similarly, boys who participate in sport activities regularly enjoy a better $\mathrm{QoL}_{\mathrm{p}}$ than boys who are not involved in sport on a regular basis.

The Relation among the Frequency of Current Sport Activity and the Quality of Life of the Child (QoL $)_{p}$

Linear regression analysis (enter model) was used to test whether the current frequency of sport activity (hours per week) can significantly predict children's $\mathrm{QoL}_{\mathrm{p}}$. According to the results of the regression analysis, the current frequency of sport activity is a significant predictor of children's $\mathrm{QoL}_{\mathrm{p}}\left(\mathrm{R}^{2}=.158\right.$, adjusted $\mathrm{R}^{2}=$ .138, $F(1,43)=8.059, p=.007, \beta=-.397, p=.007)$.

\section{Discussion}

Though there is growing interest in the role of physical activity as a potential intervention for managing the symptoms of ADHD, there is still a gap in the literature about the connection between sport participation and the QoL of children with ADHD. Therefore, the main aim of our current study was to examine whether parents of boys with ADHD who particpate in sport regularly report better QoL for their sons and less problematic behaviours and also have better global self-esteem than parents of ADHD boys who do not play sport regularly. The results showed that parents of boys who played sport on a regular basis rated their son's QoL to be significantly better than parents of boys who did not exercise regularly. The Global Problem scores (rated by the parents) were also significantly lower among boys who played sport regularly than among the physically inactive group. These results are similar to Kiluk, Weden and Culotta's [20] study results, which found that children with ADHD who played three or more sports demonstrated fewer symptoms of anxiety and depression than those who played two or fewer different kinds of sports. These findings can also be related to those presented by Gawrilow, et al. [16]. They found that lack of physical activity was shown to be related to depressed mood, more strongly in children with severe hyperactivity symptoms. Taken together, the current study and other recent studies suggest that engagement in various forms of physical activity varying in intensity can be associated with better executive functions, better social skills and lower levels of impulsivity, hyperactivity, inattention, anxiety and depression among individuals with ADHD [14-18]. It is also a noticeable result that physical activity was impressive in moderating behavioral symptoms in children with ADHD-based on parental reports [25]. Additionally, as mentioned above, parents' Global Self-Esteem scores were significantly higher among parents of boys engaged in regular sport activity than parents of boys who did not participate in regular sport activity. That means parents of boys with ADHD who played sport regularly have better global self-esteem than parents of children with ADHD who were not regular sport participants. In connection to this result, parents of children with ADHD reported lower self-confidence and less warmth and involvement with their children than the parents of control children in the Iranian population [12]. The practical impact of this result is that the child's sport participation might increase self-esteem for the parent, protecting them from potential negative consequences which can result from the child's disorder.

Next, we examined which factors could potentially predict the boys' QoL $\mathrm{p}_{\mathrm{p}}$. Only the Global Problem score proved to be a useful predictor of QoL $\mathrm{p}_{\mathrm{p}}$. Both Global Hyperactivity score and Parents' Global Self-Esteem score were excluded from the regression model. In addition to the Global Problem score, participating or not in regular sport activities was found to have a significant main

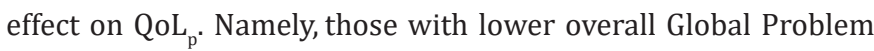
scores were reported to have better $\mathrm{QoL}_{\mathrm{p}}$ than did boys with more problematic behaviours. Likewise, boys who participate in sport activities regularly have a better $\mathrm{QoL}_{\mathrm{p}}$ than boys who are not involved in sport on a regular basis. It is known from the literature that robust reductions in $\mathrm{QoL}_{\mathrm{p}}$ were reported by parents of children with ADHD across several different $\mathrm{QoL}_{\mathrm{p}}$ measures and across a broad range of achievement, psycho-social, and selfevaluation domains (from a systematic review by Danckaerts et al.) [41]. Our results suggest that participating in regular sport activity seems to help a child with ADHD to manage his behavioral problems and can be connected to a better $\mathrm{QoL}_{\mathrm{p}}$. The severity of ADHD symptoms and the parents' global self-esteem did not seem to affect QoLp. This result can be used in the managment of boys with ADHD. In case they participate in sport activity, they might have fewer behavioral problems, which also have been supposed to be connected with better $\mathrm{QoL}_{\mathrm{p}}$

Furthermore we examined the relationship between the frequency (hours per week) of current sport activity with the children's $\mathrm{QoL}_{\mathrm{p}}$. In our study, only the current frequency of sport activity (hours per week) was a significant predictor of children's QoL $_{\mathrm{p}}$. Similarly, studies reported that boys with ADHD spend less 
time doing daily physical activity and organized sport than boys without ADHD [22,42]. These results suggest that ADHD children's sporting characteristics and behaviour should be examined thoroughly when considering their general treatment regimen, general well-being and quality of life. It is important to find out how each child can be motivated to get involved with and remain engaged in sport activities of their choise since - as our restults show - involvement with sport is an important predictor of their quality of life.

The present study should be interpreted in the context of its limitations. First, the study was cross-sectional, which made us unable to consider any causal relationship among the symptoms of ADHD, sport participation and $\mathrm{QoL}_{\mathrm{p}}$. Second, the study population included only boys the results cannot be generalised to the whole ADHD population. Third, the study population included a clinical sample only, and thus the results cannot be generalized to the population of typically developing children. Third, we used parentrated scales for the assessment of QoL, problematic behaviour characteristics, and the severity of ADHD symptoms. Parents' selfesteem was measured with a self-report questionnaire also.

\section{Conclusion}

In conclusion, we would like to highlight that frequent sport activity for a longer period can be connected to better QoL and less problematic behaviour among boys with ADHD and can have positive effects on the parents' self-esteem. Future studies should explore the potential factors that might help children with ADHD to manage their behaviour during sport, and also helping them to stay in a sport activity for a longer period of time.

\section{Declarations}

Ethics Approval and Consent to Participate: Ethical permission has been submitted and accepted on 25 January 2016 by the Ethical Committee of the Medical Research Council, Hungary (ETT-TUKEB, permission number: 56771/2016/EKU [89/16]).

Consent for Publication: Not applicable.

Availability of Data and Materials: Not applicable.

Competing Interests: The authors declare that they have no competing interests.

\section{Funding}

This work was supported by the Hungarian Scientific Research Fund (Hungarian abbreviation: OTKA, No: K-108336). Judit Balázs was supported by the János Bolyai Research Scholarship of the Hungarian Academy of Sciences.

\section{Author's Contribution}

MM was the coordinator of the study, performed the data collection, supervised the data entry, participated in data analyses and wrote the first draft of the manuscript. JF participated in designing the study and made the analyses. JB designed the study, wrote the protocol and supervised the whole procedure of the study, the data analyses and the manuscript writing. All authors read and approved the final manuscript.

\section{Acknowledgement}

We wish to thank to the patients, their parents and staff of the Vadaskert Child Psychiatric Hospital, Budapest for the collaboration with the data collection.

\section{References}

1. Brown RT, Freeman WS, Perrin JM, Stein MT, Amler RW, et al. (2001) Prevalence and Assessment of Attention-Deficit/Hyperactivity Disorder in Primary Care Setting. Pediatrics 107(3): e43.

2. Goldman LS, Genel M, Bezman RJ, Slanetz PJ (1998) Diagnosis and treatment of attention-deficit/hyperactivity disorder in children and adolescents. Council on Scientific Affairs, American Medical Association. JAMA 279(14): 1100-1107.

3. Sagvolden T, Johansen EB, Aase H, Russell VA (2005) A dynamic developmental theory of attention-deficit/hyperactivity disorder (ADHD) predominantly hyperactive /impulsive and combined subtypes. Behav Brain Sci 28: 397-419.

4. Poeta LS, Neto FR (2004) Epidemiological study on symptoms of attention deficit/hyperactivity disorder and behavior disorders in public schools of Florianopolis/SC using the EDAH. Rev Bras Psiquiatr 26(3): 150-155.

5. American Psychiatric Association. Diagnostic and statistical manual of mental disorders: DSM-5. Arlington. (2013) American Psychiatric Association, United States.

6. Barkley RA (2002) International consensus statement on ADHD. Clin Child Fam Psychol Rev 5(2): 89-111.

7. Putukian M, Kreher JB, Coppel DB, Glazer JL, McKeag DB, et al. (2011) Attention deficit hyperactivity disorder and the athlete: An American Medical Society for Sports Medicine position statement. Clin J Sport Med 21(5): 392-401.

8. Jensen PS, Hinshaw SP, Swanson JM, Greenhill LL, Conners CK, Arnold LE, et al. (2001) Findings from the NIMH multimodal treatment study of ADHD (MTA): Implications and applications for primary care providers. J Dev Behav Pediatr 22(1): 60-73.

9. Pelham WE, Fabiano GA (2008) Evidence-based psychosocial treatments for attentiondeficit/hyperactivity disorder. J Clin Child Adolesc Psychol 37(1): 184-214.

10. Harpin VA (2005) The effect of ADHD on the life of an individual, their family, and community from preschool to adult life. Arch Dis Child 90: i2-i7.

11. Murphy KR, Barkley RA (1996) Parents of children with attentiondeficit/hyperactivity disorder: Psychological and Attentional Impairment. Am J Orthopsychiatry 66(1): 93-102.

12. Alizadeh H, Applequist KF, Coolidge FL (2007) Parental selfconfidence, parenting styles, and corporal punishment in families of ADHD children in Iran. Child Abuse Negl 31(5): 567-572.

13. Haskell WL, Blair SN, Hill JO (2009) Physical activity: health outcomes and importance for public health policy. Prev Med 49(4): 280-282.

14. Gapin JI, Etnier JL (2010) The relationship between physical activity and executive function performance in children with attention-deficit hyperactivity disorder. J Sport Exerc Psychol 32(6): 753-763.

15. Gapin JI, Labban JD, Etnier JL (2011) The effects of physical activity on attention deficit hyperactivity disorder symptoms: The evidence. Prev Med 52: S70-S74. 
16. Gawrilow C, Stadler G, Langguth N, Naumann A, Boeck A (2016) Physical activity, affect, and cognition in children with symptoms of ADHD. J Atten Disord 20(2): 151-162.

17. Medina JA, Netto TLB, Muszkat M, Medina AC, Botter D, et al. (2010) Exercise impact on sustained attention of AD/HD children, methylphenidate effects. Atten Defic Hyperact Disord 2(1): 49-58.

18. Verret C, Guay M, Berthiaume C, Gardiner P, Béliveau L (2012) A physical activity program improves behavior and cognitive functions in children with ADHD: An exploratory study. J Atten Disord 16(1): 7180.

19. Conant Norville DO, Tofler IR (2005) Attention deficit/hyperactivity disorder and psychopharmacologic treatments in the athlete. Clin Sports Med 24(4): 829-843.

20. Kiluk BD, Weden S, Culotta VP (2009) Sport participation and anxiety in children with ADHD. J Atten Disord 12(6): 499-506.

21. Johnson RC, Rosén LA (2000) Sports behavior of ADHD children. Journal of Attention Disorders 4(3): 150-160.

22. Harvey WJ, Reid G, Bloom GA, Staples K, Grizenko N, et al. (2009) Physical Activity Experiences of Boys With and Without ADHD. Adapt Phys Activ Q 26(2): 131-150.

23. (1995) The world health organization QoL assessment (WHOQOL): position paper from the world health organization. Soc Sci Med 41(10): 1403-1409.

24. Marques JCB, Oliveira JA, Goulardins JB, Nascimento RO, Lima AMV, et al. (2013) Comparison of child self-reports and parent proxy-reports on quality of life of children with attention deficit hyperactivity disorder. Health Qual Life Outcomes 11: 186.

25. Gapin JI, Etnier JL (2017) Parental perceptions of the effects of exercise on behavior in children and adolescents with ADHD. J Sport Health Sci 3(4): 320-325.

26. Balázs J, Bíró A, Dálnoki D, Lefkoics E, Tamás Z, et al. (2004) A Gyermek M.I.N.I kérdőív magyar nyelvü változatának ismertetése [Introduction of the Hungarian version of the M.I.N.I Kid]. Psychiatr Hung 19: 358364

27. Lecrubier Y, Sheehan DV, Weiller E, Amorim P, Bonora I, et al. (1997) The Mini International Neuropsychiatric Interview (MINI): A short diagnostic structured interview. Reliability and validity according to the CIDI. Eur Psychiatry 12(5): 224-231.

28. Sheehan DV, Lecrubier Y, Sheehan KH, Janavs J, Weiller E, et al. (1997) The validity of the Mini International Neuropsychiatric Interview (MINI) according to the SCID-P and its reliability. Eur Psychiatry 12(5): 232-241.

29. Sheehan DV, Janavs J, Baker R, Sheehan KH, Knapp E, et al. (1998) MINI-Mini International Neuropsychiatric Interview-English Version 5.0.0-DSM-IV. J Clin Psychiatry 59: 34-57.

30. Sheehan DV, Sheehan KH, Shytle RD, Janavs J, Bannon Y, et al. (2010) Reliability and validity of the Mini International Neuropsychiatric
Interview for Children and Adolescents (MINI-KID). J Clin Psychiatry 71(3): 313-326.

31. American Psychiatric Association Diagnostic and statistical manual of mental disorders: DSM-IV-TR. American Psychiatric Association: Washington DC, USA.

32. Rosenberg M (1965) Society and the adolescent child. Princeton University Press: Princeton, New Jersey, USA.

33. Schmitt DP, Allik J (2005) Simultaneous administration of the Rosenberg Self-Esteem Scale in 53 nations: Exploring the universal and culture-specific features of global self-esteem. J Pers Soc Psychol 89(4): 623-642.

34. Sallay V, Martos T, Földvári M, Szabó T, Ittzés A (2014) A Rosenberg Önértékelés Skála (RSES-H): alternatív fordítás, strukturális invariancia és validitás. Mentálhigiéné és Pszichoszomatika 13: 259 275 .

35. Mattejat F, Simon B, König U, Quaschner K, Barchewitz C, et al. (2003) Quality of life of children and adolescents with psychiatric disorders. Results of the 1st multicenter study with an inventory to assess the quality of life in children and adolescents. Z Kinder Jugendpsychiatr Psychother 31(4): 293-303.

36. Kiss E, Baji I, Mayer L, Skultéti D, Benák I, Vetró Á (2007) Életminőség kérdőív validitása és pszichometriai jellemzői magyar gyermekpopuláción [Validity and psychometric properties of a Quality of Life Questionnaire in a Hungarian child and adolescent population]. Psychiatr Hung 22: 33-42.

37. Goodman R (2001) Psychometric properties of the Strengths and Difficulties Questionnaire. J Am Acad Child Adolesc Psychiatry 40(11): 1337-1345.

38. Birkás E, Lakatos K, Tóth I, Gervai J (2008) Screening childhood behavior problems using short questionnaires I.: the Hungarian version of the Strengths and Difficulties Questionnaire. Psychiatr Hung 23: 358-365.

39. Turi E, Gervai J, Áspán N, Halász J, Nagy P, Gádoros J (2013) Validation of the Hungarian version of the Strengths and Difficulties Questionnaire in an adolescent clinical population. Psychiatr Hung 28: 165-179.

40. DuPaul GJ, Power TJ, Anastopoulos AD, Reid R (1998) ADHD Rating Scale-IV: Checklists, Norms, and Clinical Interpretation. Guilford: New York, USA.

41. Danckaerts M, Sonuga-Barke EJS, Banaschewski T, Buitelaar J, Döpfner M, et al. (2010) The quality of life of children with attention deficit/ hyperactivity disorder: a systematic review. Eur Child Adolesc Psychiatry 19(2): 83-105.

42. Kim J, Mutyala B, Agiovlasitis S, Fernhall B (2011) Health behaviors and obesity among US children with attention deficit hyperactivity disorder by gender and medication use. Prev Med 52(3-4): 218-222. 
This work is licensed under Creative Commons Attribution 4.0 License

DOI: 10.19080/PBSIJ.2019.10.555797

\section{Your next submission with Juniper Publishers will reach you the below assets}

- Quality Editorial service

- Swift Peer Review

- Reprints availability

- E-prints Service

- Manuscript Podcast for convenient understanding

- Global attainment for your research

- Manuscript accessibility in different formats ( Pdf, E-pub, Full Text, Audio)

- Unceasing customer service

Track the below URL for one-step submission https://juniperpublishers.com/online-submission.php 